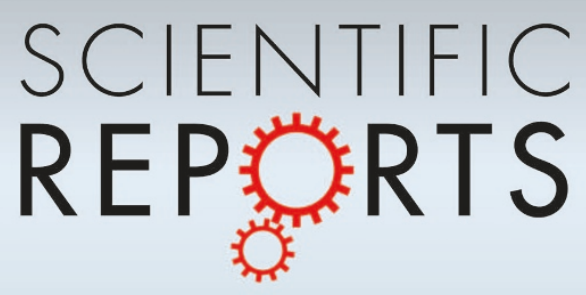

OPEN

SUBJECT AREAS:

DIAGNOSTIC MARKERS

BIOMEDICAL ENGINEERING

Received

16 June 2014

Accepted

29 July 2014

Published

9 September 2014

Correspondence and requests for materials should be addressed to

Y.N.D. (duyanan@

tsinghua.edu.cn) or

G.L.H. (tshgl@

tsinghua.edu.cn)

\section{Dew inspired breathing-based detection of genetic point mutation visualized by naked eye}

\author{
Liping Xie ${ }^{1,2}$, Tongzhou Wang' ${ }^{1}$, Tianqi Huang', Wei Hou ${ }^{4}$, Guoliang Huang' \& Yanan Du ${ }^{1,3}$
}

\begin{abstract}
'Department of Biomedical Engineering, School of Medicine, Tsinghua University, Beijing 100084, China, ${ }^{2}$ Institute of Molecular Medicine, College of Life and Health Science, Northeastern University, Shenyang 1 10004, China, ${ }^{3}$ Collaborative Innovation Center for Diagnosis and Treatment of Infectious Diseases, Hangzhou 310003, China, ${ }^{4}$ Tianjin Second People's Hospital and Tianjin Institute of Hepatology, Tianjin 300192, China.
\end{abstract}

A novel label-free method based on breathing-induced vapor condensation was developed for detection of genetic point mutation. The dew-inspired detection was realized by integration of target-induced DNA ligation with rolling circle amplification (RCA). The vapor condensation induced by breathing transduced the RCA-amplified variances in DNA contents into visible contrast. The image could be recorded by a cell phone for further or even remote analysis. This green assay offers a naked-eye-reading method potentially applied for point-of-care liver cancer diagnosis in resource-limited regions.

M olecular fingerprint analysis of genetic and epigenetic alterations of patients generates profound impact on disease diagnosis among high-risk populations ${ }^{1}$. P53 is probably the most extensively studied tumour-suppressor gene, and patients with P53 mutations are known to have a poor outcome $e^{2}$. The pre-diagnosis of specific P53 mutations in plasma are established for prevention and intervention trials for various types of cancers ${ }^{3}$. Primary liver cancer, mainly hepatocellular carcinoma (HCC), is a major cause of cancer morbidity and mortality worldwide, especially in the underdeveloped countries of Asia and sub-Saharan Africa ${ }^{4,5}$. Poor prognosis of this malignancy results in its being the third leading cause of cancer deaths in the world ${ }^{6}$. In many cases, HCCs are not diagnosed until they start to cause symptoms, at which point they may have already been at advanced stages. Mutations at codon 249 of the P53 gene are commonly found in HCCs from southern Africa and Asia in which both aflatoxin B1 (a potent hepatotoxin and hepatocarcinogen) and hepatitis B virus are the major cancer risk factors ${ }^{7}$.

Various techniques have been developed for screening mutations, including allele-specific hybridization ${ }^{8}$, primer extension by nucleotide incorporation ${ }^{9}$, electrophoresis-based methods, mass spectroscopy ${ }^{10}$, sequence analysis ${ }^{11}$ and real-time amplification refractory mutation system quantitative polymerase chain reaction assay ${ }^{12}$. Unfortunately, most of these techniques require fluorescent labelling for imaging and all of their detections require expensive instrumentations. A genotyping procedure that provides inexpensive and sensitive point mutation discrimination with few experimental and instrumental requirements would be desirable especially in the resource-limited areas.

Dew is a common natural phenomenon. It happens when moisture in warm humid air condenses on a cold substrate. Spiders' webs covered with dew are glistening in the bright sun, which make them easily visible. The dew collected on the silk reflects light, enables the webs appear brighter against the foliage. Condensation figures (CFs) provide a robust, power-free and label-free imaging method. The patterns formed by vapor condensation have long been used to test the cleanliness and uniformity of glass surfaces ${ }^{13,14}$. With ever-increasing interest in $\mathrm{CFs}$, extensive investigations have been made on the formation of CFs experimentally ${ }^{15,16}$ and theoretically ${ }^{17}$. CFs have been used to fabricate different structures such as porous materials ${ }^{18}$, as well as in designing tunable vaporcondensed nanolenses ${ }^{19}$. Various groups have used these CFs to identify patches of different types of selfassembled molecular monolayers in a number of different applications $s^{20,21}$. It is a low-cost, nondestructive method for determining surface quality in a short time (minutes) and with reasonable reproducibility ${ }^{22}$.

Inspired by the dew formation, we utilize breathing induced vapor condensation as a power-free and label-free readout for detection of liver cancer related genetic point mutation at codon 249 of P53. Rolling circle amplification (RCA) is an isothermal enzymatic polymerization technique, which can generate long single-strand DNA (ssDNA) with tens and hundreds of repeats ${ }^{23}$. The simplicity, sensitivity, robustness and low costs provide RCA a 


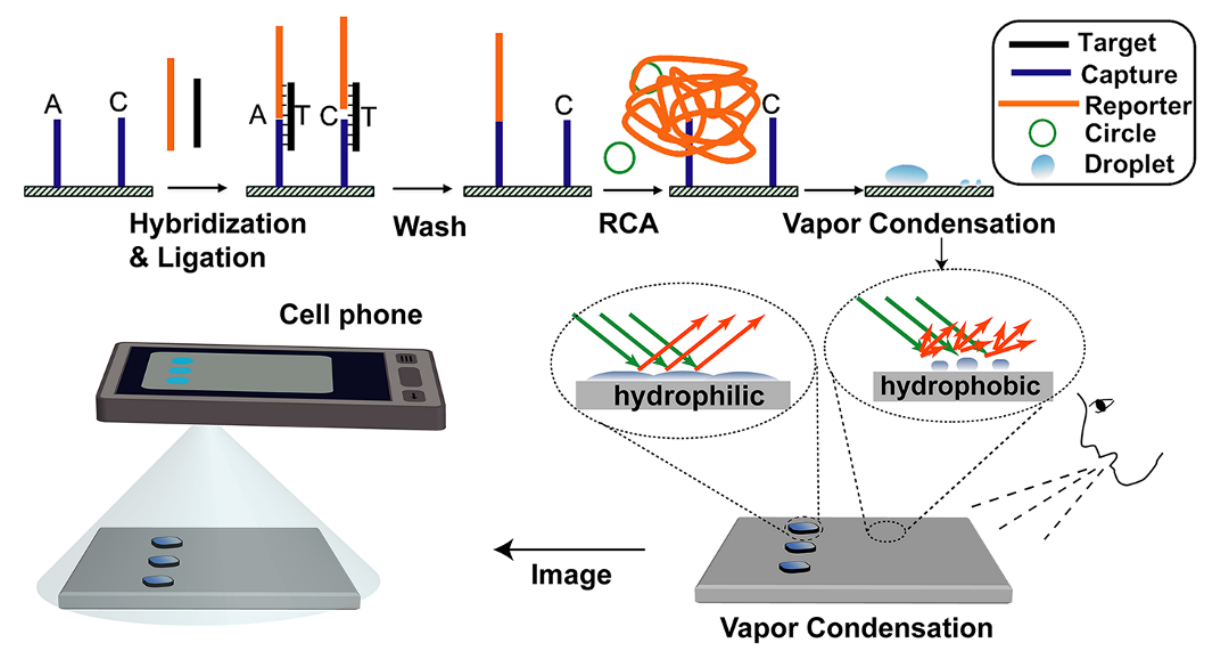

Figure 1 Schematic illustration of vapor condensation via breathing for detection of genetic point mutation, which could be visualized by naked eye and imaged by the camera in a cell phone.

distinct position among isothermal techniques for DNA diagnost$\mathrm{ics}^{24,25}$. The RCA products can reach several microns in length, and tend to collapses into a sphere, which can form hydrophilic DNA networks ${ }^{26}$. As shown in Figure 1, DNA ligation and amplification by RCA were integrated with DNA microarrays to enable identification of a single base pair mismatch within a 27 -mer single-stranded DNA target simply through breathing and naked eye visualization. Taq DNA ligase is a sequence-specific enzyme which can discriminate a single-base substitution. The ligation between the capture probe and the reporter will occur only if the oligonucleotides are perfectly paired to the complementary target DNA without gaps in-between, which will initiate RCA to generate DNA networks and finally makes the DNA microarray chip more hydrophilic. When light casts onto the chip, the hydrophilic regions covered with water films will generate more direct reflection, whereas other regions will generate more scattering, because the surface-to-volume ratio of water films are much greater than the tiny isolated droplets. As a result, the RCAamplified products on DNA array chip become visible without fluorescent labelling. The current method takes advantage of the vapor condensation induced by breathing to transduce the RCA-amplified variances in DNA contents into visible contrast. The images could be recorded by a cell phone to be saved on its memory or sent to healthcare providers for remote diagnosis through a wireless network ${ }^{27}$.

\section{Results}

Breathing-induced vapor condensation on hydrophilic-hydrophobic patterned surface. To prove the feasibility of vapor condensation on a hydrophilic-hydrophobic patterned surface as a way of readout, several hydrophilic-hydrophobic patterned glass slides were achieved by plasma-induced modification of trichloro(octadecyl) silane treated glass $^{28}$. As shown in Figure 2a, selective retention of green aqueous droplets on the hydrophilic regions was realized on the treated glass, by automatic loading and patterning of aqueous droplets, which proved successful modification of the hydrophilic-hydrophobic patterned glass slide. The molecular modified pattern of the glass at ambient condition could not be visualized by naked eye (Figure $2 \mathrm{~b}$ ). Interestingly, the desired pattern immediately appeared upon breathing onto the glass (Figure 2c).

The breathing induced vapor condensation provides a robust, power-free and label-free detection method. The contrasting phenomenon of hydrophilic and hydrophobic glass illustrates the important role of substrate properties (surface energy) on regulating the behaviour of condensed water. According to Volmer's classical nucleation theory ${ }^{29}$, the free energy barrier $(G)$ for vapor condensation on a flat surface depends strongly on the intrinsic wettability of the surface which is characterized by water contact angle $(\theta)^{30}$. G increases with $\theta$, which means less free energy barrier requires to be overcome for nucleation of a droplet on the hydrophilic $\left(0^{\circ}<\theta<\right.$ $\left.90^{\circ}\right)$ region than on the hydrophobic $\left(90^{\circ}<\theta<180^{\circ}\right)$ region. The rate of growth and coalescence of the droplets is also faster on hydrophilic region than hydrophobic region ${ }^{31}$, resulting in contrasting patterns. The moisture condensed on hydrophilic regions generates water films (diameter $>100 \mu \mathrm{m}$ ), whereas the moisture condensed on hydrophobic regions turn into many tiny isolated droplets (diameter $=1 \sim 6 \mu \mathrm{m}$ ) (Figure 3).

The process of vapor condensation including droplet nucleation, growth and coalescence are also affected by surface temperature, humidity and temperature of the surrounding environment, and vapor flow rate ${ }^{31,32}$. The vapor condensation on surface is the condensation of excessive moisture in air. There are two ways to induce vapor condensation. The first one is by decreasing the surface temperature. The saturation humidity of air around the cold surface changes with its temperature. Cooling humid warm air will lead to decrement of its saturation humidity. When the saturation humidity of air is lower than its absolute humidity, excessive moisture will be expelled from the air, forming droplets on a surface. As shown in Figure S1, the moisture first condensed into droplets (Figure S1a), then grew in size and finally coalesced into water films(Figure S1b,c) on the hydrophilic-hydrophobic patterned glass slides in a few minutes. However, it could not form vapor condensation under low humidity (e.g. in dry season or desert) by only decreasing the surface temperature ${ }^{33}$. The second way is by increasing the humidity of the surrounding air, which was demonstrated by the immediate appearance of the patterns formed by using a humidifier (video S1). Here, we combined these two ways by simply breathing to achieve air with $100 \%$ humidity and $37^{\circ} \mathrm{C}$, which will increase the humidity of the air surrounding the chip and increase the temperature difference between the chip and its surrounding air. It is the most convenient way to induce vapor condensation without precise control of the humidity and temperature of the surrounding environment. Surfaces with hydrophobic treatments can produce many tiny drops, giving the glass a frosted appearance. In contrast, surfaces with hydrophilic treatments, produces thin films of water (video S2).

The thin film of water on hydrophilic region could lead to direct light reflection resulting in much more distinct visualization than the scattered light from the hydrophobic region (Figure $2 \mathrm{~d}$ ). The image contrast of the patterned glass exhibited different appearances by varying the observation angles in the reflection mode (video S3, 


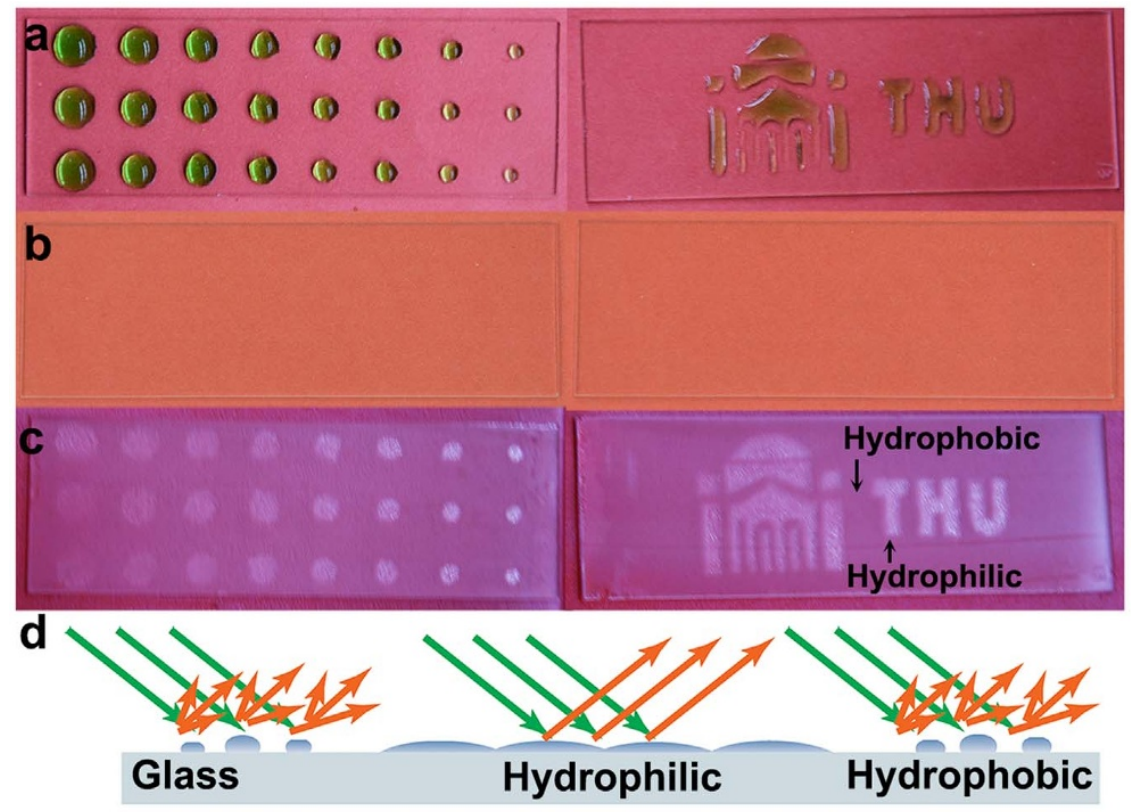

Figure $2 \mid$ Photographs of the glass slides with hydrophilic-hydrophobic patterns. (a) Patterned glass slide automatically loaded with droplets after immersion of the entire slide in green dye solution. The images of the patterned glass slides at room temperature (b) and formed with vapor condensation induced by breathing (c). (d) Optical paths on the hydrophilic and hydrophobic patterned glass slide with vapor condensation.

Figure S2). If the observing angle and the illuminating angle are symmetrical, the hydrophilic spots, which carry the water film, will be more distinct than other places because the light directly reflected are more intense than that scattered. In contrast, if the observing angle and illuminating angle are not symmetrical, the hydrophilic spot will be even dimmer than other places because all the light casted onto hydrophilic spots are directly reflected and is not collected by the cameras or eyes.

RCA-induced alteration of the surface wettability. To prove the feasibility of RCA-induced alteration of the surface wettability, we performed RCA on a DNA array chip. As shown in Figure 4a, the ssDNA splints were immobilized on a small $(3 \mathrm{~mm} \times 5 \mathrm{~mm})$ silicon chip coated with thin amine-modified $\mathrm{SiO}_{2}$ as reported in our previous paper $^{34}$, The templates bear two target complementary segments to the splints at opposite ends. Upon hybridization to the splint sequence in the presence of T4 DNA ligase, the ends of the template are brought in contact to form a circular oligonucleotide. Phi29 DNA polymerase was used for RCA to produce DNA networks. To verify that only RCA-induced DNA networks can alter the surface wettability, we setup the control group, which is compose of ssDNA with similar length as the RCA group, but cannot be amplified by RCA. As showed in Figure $4 \mathrm{~b}$, The DNA array chip is composed of $5 \times 9$ array ( 5 rows and 9 columns) with $5 \times 6$ for RCA and $5 \times 3$ as control. The diameters of the spots were approximately $50 \mu \mathrm{m}$, with $200 \mu \mathrm{m}$ center-to-center spacing. The whole chip was stained with SYBR Green II. The

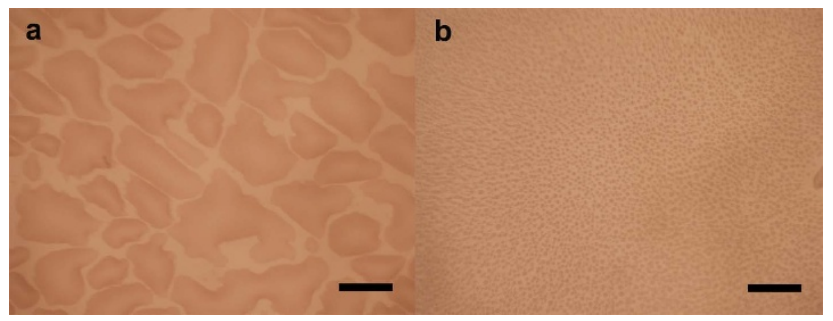

Figure 3 The droplets induced by breathing formed on the hydrophilic (a) and hydrophobic (b) regions. The scale bars are $100 \mu \mathrm{m}$.
RCA products were obviously brighter than the control group which verified that the RCA products were successfully amplified on the silica. The spots amplified by RCA automatically loaded with water droplets after immersion of the entire slide in water (video S4, S5). The DNA networks could significantly change the wettability of the chip, resulting in visible droplet arrays after water immersion (Figure S3). We could not observe anything on the DNA array chip by naked eye at room temperature (Figure 4c). But with a simple breath onto the chip, the DNA arrays amplified by RCA appeared thanks to the vapor condensation (Figure 4d, video S6). The image of the DNA arrays could be captured by a cell phone for further analysis (Figure 4e f). Cell phones enable users to have access to cost-effective and potable bio-analytical platform at any time and place. The massive volume of users ( $\sim 7$ billion worldwide) drives the rapid improvements of the hardware, software and high-end imaging embedded in cell phones ${ }^{35}$, transforming the mobile phone into an extremely powerful platform in bioanalytical sciences ${ }^{36-38}$, Here, we took advantage of the imaging system of cell phone to capture and store the breath images, or the wireless connectivity to transfer the related images to remote healthcare stations, enabling mobile healthcare delivery and personalized medicine. To minimize the operation time, we optimized the RCA reaction time. As shown in Figure S4, 30 min was enough to alter the surface to be hydrophilic. The contrast of the breathing-produced images increased with the $\mathrm{RCA}$ reaction time.

Determination of allele discrimination specificity by breathinginduced vapor condensation. To demonstrate the feasibility of this power-free and label free detection method of genetic point mutation, we integrated the target -induced DNA ligation, RCA and vapor condensation-based readout. We chose synthesized target DNA sequences designed according to the two types of predominance mutations (AGG $\rightarrow$ AGC, AGG $\rightarrow$ AGT) with a single-base mismatch at codon 249 of P53 in liver cancer patients. The target induced DNA ligation was verified by $20 \%$ polyacrylamide- $8 \mathrm{M}$ urea sequencing gel. The target ssDNA hybridized simultaneously to the capture probes and the reporter probes, and the ligation was strictly dependent on the correct sequence complementarity of the target sequence. As shown in Figure 1 and Figure S5, nucleotide A was 


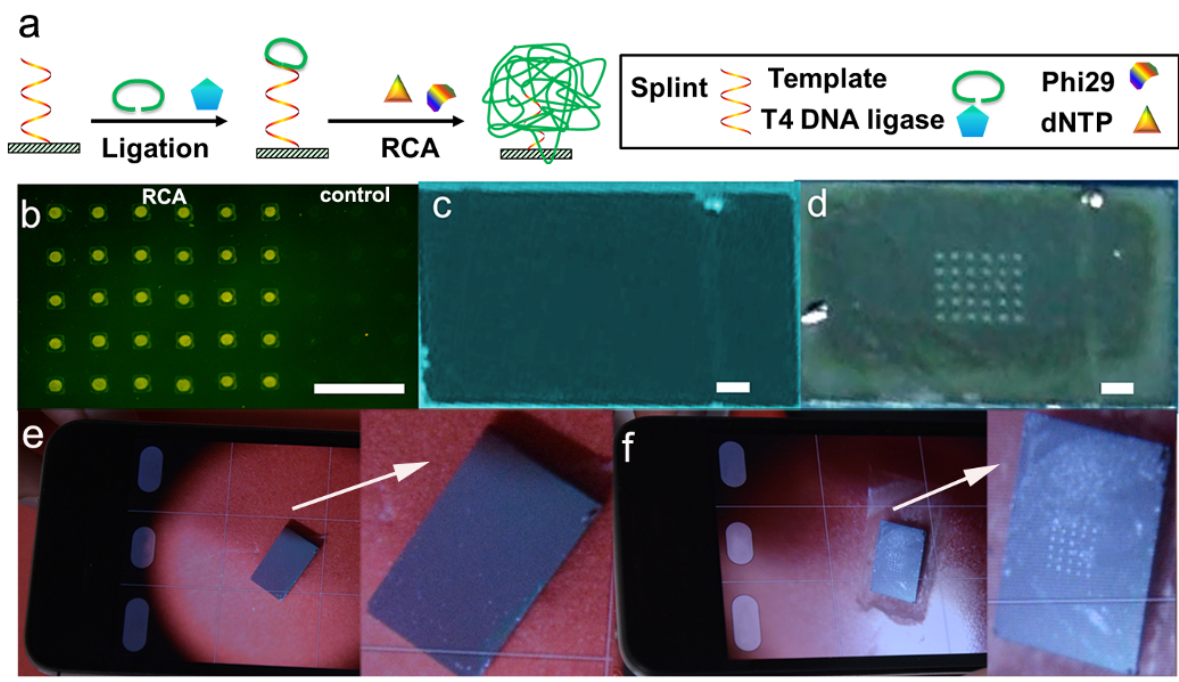

Figure $4 \mid$ DNA networks amplified by RCA alternating the wettability of the DNA chip and enabling visualization through breathing. (a) Schematic drawing of RCA process on the chip. (b) Fluorescent image of DNA chip stained with SYBR Green II. The photographs of the DNA chip processed with RCA in room temperature (c) and with vapor condensation through breathing (d). Images of the DNA chip without (e) and with (f) vapor condensation captured by a cell phone (with enlarged images as insert). The scale bars are $400 \mu \mathrm{m}$.

perfectly complementary to $\mathrm{T}$ in the target sequence (Figure S5, lane 5), whereas $\mathrm{C}$ formed a single CT mismatch (Figure S5, lane 4). The reporter probe specifically ligated to the sequence with 3 '-terminal A but not to C, since Taq DNA ligase only catalyzed the formation of a phosphodiester bond between the juxtaposed 5' -phosphate and 3'hydroxyl groups of two ssDNA when they were perfectly complementary to a hybridized target. The conformational change of the DNA led to differences in their migration rates (lane 1 and lane 4 in Figure S6a), which confirmed the successful circularization of the RCA template. The electrophoresis results of the RCA products are shown in Figure S6b, the RCA products were observed in lane 3 in the present of reporter probes, showing extremely low mobility. While no band appeared in lane 2 without reporter probes, indicating no RCA products were generated in the negative control. The results demonstrated that target induced ligation combined with RCA could be used for point mutation detection.

To discriminate genetic point mutation on a chip by breathinginduced vapor condensation, a silicon chip with $\mathrm{SiO}_{2}$ coating was immobilized with capture probes (AGG, AGC, AGT), each in $2 \times 6$ repeats (Figure $5 \mathrm{a}$ ). The array probes differ only by the last nucleotide at their $3^{\prime}$ ends. When targets, reporter probes, and Taq DNA ligase were simultaneously introduced to the array chip, surface duplexes formed on the array chip. However, ligation only occurred if the duplexes were perfectly complementary. After denaturation with a stringent wash $(0.01 \mathrm{M} \mathrm{NaOH})$, the perfectly matched probes were extended with the reporter sequence, while the mismatched probes returned to its original state. The extended probes could be subsequently amplified with RCA process, which altered the property of the surface from being hydrophobic to hydrophilic, resulting in the change of the light propagation mode. The capturing angle affected the imaging modality (Figure S7) as demonstrated previously. For easy operation, this experiment chose a non-direct-reflection angle where areas with scattering appear brighter than areas with direct reflection. As shown in Figure $5 \mathrm{~b} \sim \mathrm{d}$ and video S7, a distinct signal could be observed for the corresponding capture probe spots, and only in the presence of each respective target. The detection concentration was down to $1 \mathrm{nM}$ (Figure S8). This assay which based on traditional rolling circle amplification possesses high selectivity for discriminating genetic point mutation ${ }^{39}$. In order to further facilitate end users, we will improve the overall approach in the future study. According to literatures, several isothermal amplification methods with higher efficiency and easier operation have been developed, such as hyperbranched rolling circle amplification (HRCA) ${ }^{40}$ and target sequence recycled rolling circle amplification (TR-RCA ${ }^{41}$, which provide good references for improving the current breathing-induced detection based on vapor condensation.

\section{Discussion}

In summary, a nature-inspired method based on vapor condensation was reported for discriminating liver cancer related genetic point mutation. Proof-of-concept detection of synthesized 27-mer ssDNA target (a single-base mismatch at codon 249 of P53, AGG $\rightarrow$ AGC and AGG $\rightarrow$ AGT) was accomplished which validated the usefulness of this platform. The DNA networks induced by the amplified targets altered the wettability of the detection spots. Vapor condensation as a readout could transduce the wettability changes of the chip to visualized signals. It provides a power-free, label-free and naked-eye-reading way to detect genetic point mutation in the

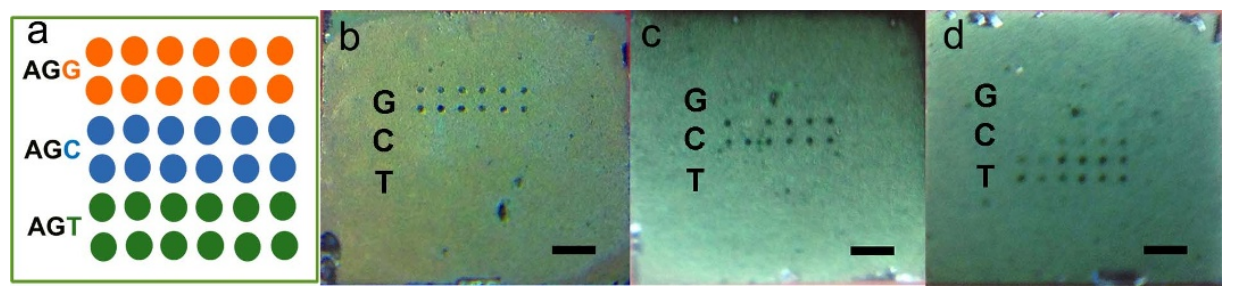

Figure $5 \mid$ Multiplex detection of genetic point mutations. (a) Schematics of the DNA array with three different capture probes. (b) $\sim$ (d) Images of the RCA-amplified chip with the wild type sequence (AGG) and two point mutations (AGG $\rightarrow$ AGC and AGG $\rightarrow$ AGT) which were visualized by vapor condensation via breathing and captured by a cell phone. The scale bars are $400 \mu \mathrm{m}$. 
absence of any instrument. This method which can be potentially applied for point-of-care molecular diagnosis, is of practical importance in remote and resource-poor settings. The real-time resultsimages can also be remotely accessed by certified professionals, thereby enabling the monitoring of emerging situations. In the future study, we will apply it on the detection of more complex samples (e.g. real sample from patients) upon further optimization.

\section{Methods}

Materials. Octadecyltrichlorosilane(OTS) was purchased from Sigma-Aldrich. The following phosphate buffer was used in the experiment: phosphate buffered saline with tween 20 (PBST) $\left(137 \mathrm{mM} \mathrm{NaCl}, 2.7 \mathrm{mM} \mathrm{KCl}, 10 \mathrm{mM}, \mathrm{Na}_{2} \mathrm{HPO}_{4} \cdot 12 \mathrm{H}_{2} \mathrm{O}\right.$, $2 \mathrm{mM} \mathrm{KH}_{2} \mathrm{PO}_{4}, 0.1 \%$ Tween 20). T4 DNA ligase was purchased from TaKaRa. RepliPHI ${ }^{\mathrm{TM}}$ Phi29 reagent set was purchased from EpiCentre (Chicago,USA). SYBR Green II was purchased from Biohao (Beijing,China). EXO I and EXO III were purchased from New England Biolabs Inc (Ipswich, United States). The following oligonucleotides showed in table S1 were synthesized from the Sangon Biotech Co., Ltd (Shanghai, China), and purified by High Performance Liquid Chromatography. Silicon wafers (B-doped, 100) were provided by CapitalBio (Beijing, China). All aqueous solutions were prepared with deionized water $(18 \mathrm{M} \Omega \cdot \mathrm{cm})$.

Fabrication of hydrophilic and hydrophobic patterned glass slides. Briefly, to make the glass slides hydrophobic, the cleaned glass slides were immersed in $1 \%$ trichloro(octadecyl) silane (OTS)/n-hexane solution for $10 \mathrm{~min}$. Excess OTS was rinsed off with ethanol before drying at $60^{\circ} \mathrm{C}$ for another $4 \mathrm{~h}$. To construct the hydrophilic-hydrophobic patterned glass slide, a poly(dimethylsiloxane) (PDMS) stamp with pre-designed patterns was pressed onto the OTS-treated glass and then exposed to oxygen plasma with power of $12 \mathrm{~W}$ for $60 \mathrm{~s}$ to locally convert the terminal groups of the OTS in exposed regions to hydroxyl groups. The PDMS stamps retained excellent conformation and could thus be reused.

Fabrication of gene chip. Micro-carriers were prepared by thermo oxidizing $\mathrm{p}++$ type, B-doped, (100)-oriented silicon with resistivity $<1 \mathrm{mU} \mathrm{cm}$. The $680 \mathrm{~nm} \mathrm{SiO}{ }_{2}$ layer was grown at $1000^{\circ} \mathrm{C}$ by thermal oxidation in $\mathrm{H}_{2}$ and $\mathrm{O}_{2}$ ambient environment at atmospheric pressure. After thermo oxidation, the silicon wafer with a top layer of thermally grown $\mathrm{SiO}_{2}$ was cut into $3 \times 5 \mathrm{~mm}$ chips with a dicing machine (DAD-321, DISCO Corp., Japan). Then, the micro-carriers were placed in a solution of $1 \mathrm{M}$ $\mathrm{NaOH}$ for $10 \mathrm{~min}$, rinsed in deionized water, and dried by $\mathrm{N}_{2}$. The dried microcarriers were amino silanized by immediately placing them in a solution of $10 \%$ (vol/ vol) (3-aminopropyl)triethoxysilane in ethanol for $20 \mathrm{~min}$, and then rinsing for $5 \mathrm{~min}$ in ethanol for three times, then $120^{\circ} \mathrm{C}$ for $3 \mathrm{~h}$. The splint was re-suspended at a concentration of $5 \mu \mathrm{M}$ in $50 \%$ dimethyl sulfoxide and printed by SmartArrayer ${ }^{\mathrm{TM}} 48$ Microarray Spotter (CapitalBio, China).

Verification of the feasibility of the detection method. The chip immobilized with $5 \mu \mathrm{M}$ splint-1 ssDNA sequence and control splint ssDNA sequence as predesigned gene array. Prior to use, the chip was washed with PBST and $\mathrm{dH}_{2} \mathrm{O}$, respectively. Then, $4.5 \mu \mathrm{M}$ template- 1 was added onto the chip and heated up to $60^{\circ} \mathrm{C}$ for $15 \mathrm{~min}$ in an airtight chamber, and cooled down to room temperature. Then, $8 \mathrm{U} / \mu \mathrm{L}$ T4 DNA ligase mixed with T4 DNA ligation buffer (66 mM PH 8.0 Tris- $\mathrm{HCl}$ buffer, $6.6 \mathrm{mM} \mathrm{MgCl}_{2} 10 \mathrm{mM}$ dithiothreitol, $1 \mathrm{mM} \mathrm{ATP}$ ) was added and incubated at $22^{\circ} \mathrm{C}$ for $4 \mathrm{~h}$. RCA reaction was carried out at $30^{\circ} \mathrm{C}$ for $12 \mathrm{~h}$ in Phi29 reaction buffer ( $40 \mathrm{mM}$ Tris- $\mathrm{HCl}(\mathrm{pH}=7.5), 50 \mathrm{mM} \mathrm{KCl}, 10 \mathrm{mM} \mathrm{MgCl}_{2}, 5 \mathrm{mM}\left(\mathrm{NH}_{4}\right)_{2} \mathrm{SO}_{4}, 4 \mathrm{mM}$ DTT) with $5 \mathrm{U} / \mu \mathrm{L}$ Phi29 polymerase, $880 \mu \mathrm{M}$ dNTP. Finally, the chip was completely washed with PBST and $\mathrm{dH}_{2} \mathrm{O}$.

Determination of allele discrimination specificity in solution. Hybridization of the target with $5^{\prime}$-phosphorylated ssDNA 47-mer reporter probes and the 19-mer capture probes which differ by only the last nucleotide at their 3 '-terminals was carried out in $22 \mu \mathrm{L}$ buffer containing $20 \mathrm{mM}$ Tris- $\mathrm{HCl}(\mathrm{pH}=7.6), 25 \mathrm{mM}$ potassium acetate, $10 \mathrm{mM}$ dithiothreitol, $10 \mathrm{mM}$ magnesium acetate, $1 \mathrm{mM}$ nicotinamide adenosine dinucleotides, $10 \mathrm{mM}$ DTT, $0.1 \%$ Triton X-100, $3.6 \mu \mathrm{M}$ linear capture probe, $3.6 \mu \mathrm{M}$ reporter probe, $1.8 \mu \mathrm{M}$ target and $0.8 \mathrm{U} / \mu \mathrm{L}$ of Taq DNA ligase at $60^{\circ} \mathrm{C}$ for $1 \mathrm{~h}$. The results were analyzed by $20 \%$ urea denaturing polyacrylamide gel.

Preparation of circular DNA template for RCA. $4 \mu \mathrm{M}$ of template- 2 and $4 \mu \mathrm{M}$ of splint-2 were mixed in $20 \mu \mathrm{L}$ of ligation buffer $(66 \mathrm{mM} \mathrm{PH} 8.0$ Tris- $\mathrm{HCl}$ buffer, $6.6 \mathrm{mM} \mathrm{MgCl}_{2} 10 \mathrm{mM}$ dithiothreitol, $1 \mathrm{mM} \mathrm{ATP}$ ), and annealed together by heating up to $90^{\circ} \mathrm{C}$ for $5 \mathrm{~min}$, and then cooled to room temperature. $175 \mathrm{U}$ of T4 DNA ligase and $1 \mathrm{mM}$ ATP was added and incubated at $16^{\circ} \mathrm{C}$ for $12 \mathrm{~h}$. After ligation, T4 DNA ligase was inactivated by heating the reaction mixture at $65^{\circ} \mathrm{C}$ for $10 \mathrm{~min}$. The samples were treated with $10 \mathrm{U}$ ExoI and $40 \mathrm{U}$ ExoIII enzymes that digested ss- and ds-DNA respectively, and separated by $20 \%$ urea denaturing polyacrylamide gel.

RCA reaction in solution. After circle ligation, two parallel groups of experiments were conducted. One group marked with $+\mathrm{R}$ was with adding $2 \mu \mathrm{L}$ reporter probes. The control group marked with $-\mathrm{R}$ was with adding $2 \mu \mathrm{L} \mathrm{dH}_{2} \mathrm{O}$. Polymerization was carried out at $30^{\circ} \mathrm{C}$ for $1 \mathrm{~h}$ in $16 \mu \mathrm{L}$ of Phi29 reaction buffer $(40 \mathrm{mM}$ Tris- $\mathrm{HCl} \mathrm{pH}=$ $7.5,50 \mathrm{mM} \mathrm{KCl}, 10 \mathrm{mM} \mathrm{MgCl}_{2}, 5 \mathrm{mM}\left(\mathrm{NH}_{4}\right)_{2} \mathrm{SO}_{4}, 4 \mathrm{mM}$ DTT) with $5 \mathrm{U} / \mu \mathrm{L}$ Phi29 polymerase, $880 \mu \mathrm{M}$ dNTP and $4 \mu \mathrm{L}$ circlar template. The RCA products were analyzed by $1 \%$ agarose gel electrophoresis.

Genetic point mutation discrimination by the on-chip detection. The chip immobilized with $5 \mu \mathrm{M}$ capture probes (249AGCcaptu/249AGTcaptu/249captu) as predesigned gene array. Prior to use, the chip was washed with $\mathrm{PBST}$ and $\mathrm{dH}_{2} \mathrm{O}$, respectively. The point mutation discrimination was carried out in a solution containing $5 \mu \mathrm{M}$ reporter probe mixed with the targets in Taq DNA liagase buffer (20 mM Tris- $\mathrm{HCl}$ ( $\mathrm{pH} 7.6), 25 \mathrm{mM}$ potassium acetate, $10 \mathrm{mM}$ dithiothreitol, $10 \mathrm{mM}$ magnesium acetate, $1 \mathrm{mM}$ nicotinamide adenosine dinucleotides, $10 \mathrm{mM} \mathrm{DTT}, 0.1 \%$ Triton X-100) by $0.8 \mathrm{U} / \mu \mathrm{L}$ of Taq DNA ligase at $60^{\circ} \mathrm{C}$ for $1 \mathrm{~h}$. Then, the chip was incubated in $0.01 \mathrm{M} \mathrm{NaOH}$ solution for $5 \mathrm{~min}$ to remove the un-ligation probe. The template-2 ssDNA sequence was added onto the chip and heated up to $60^{\circ} \mathrm{C}$ for $15 \mathrm{~min}$ in a humidified chamber, and cooled down to room temperature. Then, $8 \mathrm{U} /$ $\mu \mathrm{L}$ T4 DNA ligase mixed with T4 DNA ligation buffer $(66 \mathrm{mM}$ PH 8.0 Tris- $\mathrm{HCl}$ buffer, $6.6 \mathrm{mM} \mathrm{MgCl}_{2} 10 \mathrm{mM}$ dithiothreitol, $1 \mathrm{mM} \mathrm{ATP}$ ) was added and incubated at $22^{\circ} \mathrm{C}$ for $4 \mathrm{~h}$. RCA reaction was carried out at $30^{\circ} \mathrm{C}$ for $12 \mathrm{~h}$ in Phi29 reaction buffer (40 mM Tris- $\mathrm{HCl}(\mathrm{pH}=7.5), 50 \mathrm{mM} \mathrm{KCl}, 10 \mathrm{mM} \mathrm{MgCl}, 5 \mathrm{mM}\left(\mathrm{NH}_{4}\right)_{2} \mathrm{SO}_{4}, 4 \mathrm{mM}$ DTT) with $5 \mathrm{U} / \mu \mathrm{L}$ Phi29 polymerase, $880 \mu \mathrm{M}$ dNTP. Finally, the chip was washed with PBST and $\mathrm{dH}_{2} \mathrm{O}$.

1. Marx, J. DNA Arrays Reveal Cancer in Its Many Forms. Science 289, 1670-1672 (2000).

2. Soussi, T. \& Beroud, C. Assessing TP53 status in human tumours to evaluate clinical outcome. Nat Rev Cancer 1, 233-239 (2001).

3. Jackson, P. E. et al. Prospective detection of codon 249 mutations in plasma of hepatocellular carcinoma patients. Carcinogenesis 24, 1657-1663 (2003).

4. Jemal, A. et al. Global cancer statistics. CA-Cancer J Clin 61, 69-90 (2011).

5. Groopman, J. D., Kensler, T. W. \& Wild, C. P. Protective interventions to prevent aflatoxin-induced carcinogenesis in developing countries. Annu Rev Public Health 29, 187-203 (2008).

6. Zhao, P., Dai, M., Chen, W. \& Li, N. Cancer Trends in China. Jpn J Clin Oncol 40, 281-285 (2010).

7. Hsu, I. C. et al. Mutational hot spot in the p53 gene in human hepatocellular carcinomas. Nature 350, 427-428 (1991).

8. Howell, W. M., Jobs, M., Gyllensten, U. \& Brookes, A. J. Dynamic allele-specific hybridization. Nat Biotechnol 17, 87-88 (1999).

9. Lovmar, L. et al. Microarrays for genotyping human group a rotavirus by multiplex capture and type-specific primer extension. J Clin Microbiol 41, 5153-5158 (2003).

10. Oberacher, H., Niederstätter, H., Casetta, B. \& Parson, W. Detection of DNA Sequence Variations in Homo- and Heterozygous Samples via Molecular Mass Measurements by Electrospray Ionization Time-of-Flight Mass Spectrometry. Anal Chem 77, 4999-5008 (2005).

11. Wang, Y. C. et al. Mutations of Cx26 gene (GJB2) for prelingual deafness in Taiwan. Eur J Hum Genet 10, 495-498 (2002).

12. Bai, R. K. \& Wong, L. J. Detection and quantification of heteroplasmic mutant mitochondrial DNA by real-time amplification refractory mutation system quantitative PCR analysis: a single-step approach. Clin Chem 50, 996-1001 (2004).

13. Lord, R. Breath figures. Nature 86, 416-417 (1911).

14. Aitken, J. Breath figures. Nature 90, 619-627 (1913).

15. Beysens, D. \& Knobler, C. M. Growth of Breath Figures. Phys. Rev. Lett. 57, 1433-1436 (1986).

16. Fritter, D., Knobler, C. M. \& Beysens, D. A. Experiments and simulation of the growth of droplets on a surface (breath figures). Phys Rev A 43, 2858-2869 (1991)

17. Family, F. \& Meakin, P. Kinetics of droplet growth processes: Simulations, theory, and experiments. Phys. Rev. A 40, 3836-3854 (1989).

18. Bai, H., Du, C., Zhang, A. \& Li, L. Breath figure arrays: unconventional fabrications, functionalizations, and applications. Angew Chem Int Ed Engl 52, 12240-12255 (2013).

19. McLeod, E. et al. Tunable Vapor-Condensed Nanolenses. ACS Nano 8, 7340-7349 (2014).

20. Erath, J. et al. Phototunable Surface Interactions. Langmuir 29, 12138-12144 (2013).

21. Lopez, G. P., Biebuyck, H. A., Frisbie, C. D. \& Whitesides, G. M. Imaging of features on surfaces by condensation figures. Science 260, 647-649 (1993).

22. Hofer, R., Textor, M. \& Spencer, N. D. Imaging of Surface Heterogeneity by the Microdroplet Condensation Technique. Langmuir 17, 4123-4125 (2001).

23. Zhao, W., Ali, M., Brook, M. \& Li, Y. Rolling Circle Amplification: Applications in Nanotechnology and Biodetection with Functional Nucleic Acids. Angew Chem Int $E d$ 47, 6330-6337 (2008).

24. Najafzadeh, M. J., Sun, J., Vicente, V. A. \& de Hoog, G. S. Rapid identification of fungal pathogens by rolling circle amplification using Fonsecaea as a model. Mycoses 54, e577-e582 (2011).

25. Wang, Y. et al. Fluorescence and Visual Detection of Single Nucleotide Polymorphism Using Cationic Conjugated Polyelectrolyte. Langmuir 28, 889-895 (2011)

26. Lee, J. B., Hong, J., Bonner, D. K., Poon, Z. \& Hammond, P. T. Self-assembled RNA interference microsponges for efficient siRNA delivery. Nat Mater 11, 316-322 (2012). 
27. Zhu, H. et al. Cost-effective and rapid blood analysis on a cell-phone. Lab Chip 13, 1282-1288 (2013).

28. Xie, L., Yan, X. \& Du, Y. An aptamer based wall-less LSPR array chip for label-free and high throughput detection of biomolecules. Biosens Bioelectron 53, 58-64 (2014).

29. Sigsbee, R. A. Nucleation. (Marcel Dekker, New York, 1969).

30. Varanasi, K. K., Hsu, M., Bhate, N., Yang, W. \& Deng, T. Spatial control in the heterogeneous nucleation of water. Appl Phys Lett 95, 94101 (2009).

31. Leach, R. N., Stevens, F., Langford, S. C. \& Dickinson, J. T. Dropwise Condensation: Experiments and Simulations of Nucleation and Growth of Water Drops in a Cooling System. Langmuir 22, 8864-8872 (2006).

32. Ucar, I. O. \& Erbil, H. Y. Use of diffusion controlled drop evaporation equations for dropwise condensation during dew formation and effect of neighboring droplets. Colloids Surf A Physicochem Eng Asp 411, 60-68 (2012).

33. Beysens, D. et al. Comment on "The moisture from the air as water resource in arid region: Hopes, doubt and facts" by Kogan and Trahtman. J Arid Environ 67, 343-352 (2006).

34. Wang, T. et al. Label-free biomolecular imaging using scanning spectral interferometry. Chin. Opt. Lett. 11, 111102 (2013).

35. Ozcan, A. Mobile phones democratize and cultivate next-generation imaging, diagnostics and measurement tools. Lab Chip DOI: 10.1039/C4LC00010B (2014).

36. Vashist, S. K., Mudanyali, O., Schneider, E. M., Zengerle, R. \& Ozcan, A. Cellphone-based devices for bioanalytical sciences. Anal Bioanal Chem 406, 3263-3277 (2014)

37. Coskun, A. F., Nagi, R., Sadeghi, K., Phillips, S. \& Ozcan, A. Albumin testing in urine using a smart-phone. Lab Chip 13, 4231-4238 (2013).

38. Coskun, A. F. et al. A personalized food allergen testing platform on a cellphone. Lab Chip 13, 636-640 (2013).

39. Lizardi, P. M. et al. Mutation detection and single-molecule counting using isothermal rolling-circle amplification. Nat Genet 19, 225-232 (1998).

40. Kaocharoen, S. et al. Hyperbranched rolling circle amplification as a rapid and sensitive method for species identification within the Cryptococcus species complex. Electrophoresis 29, 3183-3191 (2008).

41. Long, Y., Zhou, X. \& Xing, D. An isothermal and sensitive nucleic acids assay by target sequence recycled rolling circle amplification. Biosens Bioelectron 46, 102-107 (2013).

\section{Acknowledgments}

We thank all Du-lab members for general assistance. This work is financially ported by the Natural Science Foundation of China $(81327005,81171474,51273106)$.

\section{Author contributions}

Y.N.D. and G.L.H. supervised and directed the overall project. L.P.X. conceived the experiments and wrote the main manuscript text. L.P.X. and T.Z.W. performed experiments and contributed equally to this work. L.P.X., Y.N.D., T.Z.W. and G.L.H. contributed to the experimental design and data analysis. T.Q.H. assisted L.P.X. with Figure S5. W.H. helped write the manuscript. All authors contributed to review the manuscript.

\section{Additional information}

The corresponding author is responsible for submitting a competing financial interests statement on behalf of all authors of the paper.

Supplementary information accompanies this paper at http://www.nature.com/ scientificreports

Competing financial interests: The authors declare no competing financial interests.

How to cite this article: Xie, L. et al. Dew inspired breathing-based detection of genetic point mutation visualized by naked eye. Sci. Rep. 4, 6300; DOI:10.1038/srep06300 (2014).

This work is licensed under a Creative Commons Attribution-NonCommercialShareAlike 4.0 International License. The images or other third party material in this article are included in the article's Creative Commons license, unless indicated otherwise in the credit line; if the material is not included under the Creative Commons license, users will need to obtain permission from the license holder in order to reproduce the material. To view a copy of this license, visit http:// creativecommons.org/licenses/by-nc-sa/4.0/ 